and of creep encountered in TKR designs are the direct result of failing to allow adequately in the design for the properties of the materials. Thus, no modification of material or new composition will necessarily improve the performance of the total joint replacement. The acquisition of improved materials with wellcharacterised mechanical and biological performance will lead to improved total joint replacements only if sound new designs evolve.

JONATHAN BLACK

Professor Jonathan Black, Ph.D., Orthopaedic Surgery Research, 127 Old Medical School, University of Pennsylvania. 36th Street and Hamilton Walk, Philadelphia, Pennsylvania 19104, United States of America.

\title{
REFERENCES
}

Charnley, J. (1976) Remarks, Eastern Orthopaedic Society, Bermuda.

Charnley, J. (1977) A review of 10,000 total hip replacements. Address to the Ninth International Biomaterials Symposium, New Orleans.

Charosky, C. B., Bullough, P. G., and Wilson, P. D., Jun. (1973) Total hip replacement failures: A histological evaluation. Journal of Bone and Joint Surgery, 55-A, 49-58.

Cracchiolo, A. 3rd (1976) Statistics of total knee replacement. Clinical Orthopaedics and Related Research, 120, 2-3.

Dumbleton, J. H., Shen, C., and Miller, E. H. (1974) A study of the wear of some materials in connection with total hip replacement. Wear. 29, 163-171.

Homsy, C. A. (1970) Bio-compatibility in selection of materials for implantation. Journal of Biomedical Materials Rescarch, 4, $341-356$.

Kettlekamp, D. B., and Nasca, R. (1973) Biomechanics and knee replacement arthroplasty. Clinical Orthopaedics and Related Research, 94, 8-14.

Laing, P. G. (1973) Compatibility of biomaterials. Orthopedic Clinics of North America, 4, 249-273.

Péan, J. E. (1894) Des moyens prosthétiques destinés à obtenir la réparation de parties ossueses. Gazette des hôpitaux civils et militaires, 67, 290-292. Translated by Bick, E. M. (1973) Clinical Orthopaedics and Related Research, 94, 4-7.

Revell, P. A., Weightman, B., Roberts, B. V., and Freeman, M. A. R. (1978) The production of polyethylene wear debris. Personal communication from M. A. R. Freeman.

Richardson, M. O. W. (1971) Chemical aspects of wear processes in polymers-A review. Wear, 17, 89-99.

Shen, C., and Dumbleton, J. H. (1974) The friction and wear behavior of irradiated very high molecular weight polyethylene. Wear, 30, 349-364.

Shoji, H., D'Ambrosia, R. D., and Lipscombe, P. R. (1976) Failed polycentric total knee prostheses. Journal of Bone and Joint Surgery, 58-A, 773-777.

Willert, H.-G., Ludwig, J., and Semlitsch, M. (1974) Reaction of bone to methacrylate after hip arthroplasty. Journal of Bone and Joint Surgery, 56-A, 1368-1382.

\section{THE TRAINING OF ORTHOTISTS}

Many, and often bitter, complaints are made by patients and doctors about orthoses and no one disputes the need for a very considerable improvement in quality, delivery and research. It is the means that are debated. As a step in this direction formal training has been instituted for Orthotists in England and Wales by the Orthotic Training Council set up by the Department of Health and Social Security in 1972 for this purpose, and in Scotland for combined Orthotists and Prosthetists by the National Centre at Strathclyde. As always, the problem of transforming an empirical craft into a scientific discipline presents many problems and options and the Orthotic Training Council has instituted an inherently flexible system, capable of evolution both in regard to future organisation and to the maintenance of adequate education and technical standards in the light of advancing knowledge. A four-year course has been adopted with three academic periods, each of ten weeks, within a technical college, interspersed with three in-service years with the firm sponsoring the student. Both are monitored by appropriate examinations and the in-service training by the appointment of a training officer in each firm. The student is required to work through a task book of some fifty-two tasks at approximately fortnightly intervals covering the whole spectrum of orthotic fitting. In addition the firms are visited at regular intervals by orthotic and engineering assessors to discuss problems and standards of education. In the final year a research project has to be undertaken. In addition to this course, postgraduate refresher courses are held at regular intervals and it is hoped to institute a formal course for the advanced training of orthotists wishing to teach and to engage in research.

In June 1977 the first two students qualified for the Diploma of the Orthotic Training Council, four are due to sit the examination this year and ten the next. After June 1982 no orthotist will be able to work for the National Health Service unless he possesses an acceptable qualification.

All such schemes contain many imperfections. At present the entrance level is wide and variable. In the very near future it will be possible and desirable to raise this level quite considerably. Similarly the question of joining the Council for Professions Supplementary to Medicine is under urgent consideration. 
A beginning has been made but a vital factor both in the success of training and the ultimate function of orthotists is the interest, knowledge and involvement of the consultant who is "responsible for ensuring that each complete appliance conforms to the prescription and is satisfactory in manufacture, fit and function when fitted to the patient" (Department of Health and Social Security 1978), an obligation often "more honour'd in the breach than the observance". One can understand that the orthosis is now somewhat overshadowed by the more glamorous internal prosthesis, but a recent paper
(Jacobson and Mason 1977) suggests that there is an important place for both in a correctly balanced scheme of treatment. In scoliosis and in spina bifida orthoses make unique contributions, as they can do in many other fields if the necessary research is undertaken in close cooperation with, if not initiated by, the medical prescriber. Such research will depend on the survival and enlargement of hospital workshops, which are at present tending to decay rather than to expand, although there are signs that this danger is now being recognised and, one hopes, countered in time. G. K. ROSE

G. K. Rose, F.R.C.S., Senior Consultant Orthopaedic Surgeon, Orthotic Research and Locomotor Assessment Unit, The Robert Jones and Agnes Hunt Orthopaedic Hospital, Oswestry, Shropshire SY10 7A'G, England.

\section{REFERENCES}

Jacobson, T., and Mason, A. (1977) An orthosis for a patient with a failed hip prosthesis. Orthotics and Prosthetics, 31 (2), 27. Department of Health and Social Security (1978) Provision of Medical and Surgical Appliances, p.6, para. 45. London: Department of Health and Social Security. 